\title{
Little evidence of systemic and adipose tissue inflammation in overweight individuals ${ }^{\dagger}$
}

\author{
Charmaine S. Tam, Jeffrey D. Covington, Eric Ravussin and Leanne M. Redman* \\ for the Pennington CALERIE Team
}

Pennington Biomedical Research Center, Louisiana State University System, Baton Rouge, LA, USA

\section{Edited by:}

Julie Mattison, National Institutes of

Health, USA

\section{Reviewed by:}

Adam Salmon, University of Texas

Health Science Center at

San Antonio, USA

Ricki Colman, University of

Wisconsin, USA

${ }^{*}$ Correspondence:

Leanne M. Redman, Pennington

Biomedical Research Center,

Louisiana State University System,

6400 Perkins Road, Baton Rouge,

LA 70808, USA.

e-mail: leanne.redman@pbrc.edu

${ }^{\dagger}$ Clinical Trial Registration Number: CALERIE, NCT00099151

(www.clinicaltrials.gov)
Context: The effect of weight loss by diet alone or diet in conjunction with exercise on low-grade inflammation in non-obese (overweight) individuals is not known. Objective: Test the hypothesis that 24 weeks of moderate calorie restriction (CR; $25 \%$ ) by diet only or with aerobic exercise would reduce markers of systemic inflammation and attenuate inflammation gene expression in subcutaneous adipose tissue. Design: Randomized controlled trial. Setting: Institutional Research Center. Participants: Thirty-five overweight (body mass index: $27.8 \pm 0.7 \mathrm{~kg} / \mathrm{m}^{2}$ ) but otherwise healthy participants $(16 \mathrm{M} / 19 \mathrm{~F}) \mathrm{com}$ pleted the study. Intervention: Participants were randomized to either CR $25 \%$ reduction in energy intake, $n=12$ ), caloric restriction + exercise (CR + EX: $12.5 \%$ reduction in energy intake $+12.5 \%$ increase in exercise energy expenditure, $n=12$ ), or control (healthy weight-maintenance diet, $n=11$ ) for 6 months. Main outcome measures: Fasting serum markers of inflammation [leptin, highly sensitive C-reactive protein (hsCRP), interleukin-6 (IL-6), tumor necrosis factor-alpha (TNF- $\alpha$ ), adiponectin] and inflammationrelated genes [CD68, IL-6, TNF- $\alpha$, macrophage migration inhibitory factor (MIF), monocyte chemoattractant protein-1 (MCP-1), adiponectin, plasminogen activator inhibitor-1 (PAI1)] in subcutaneous adipose tissue. Results: $C R$ and $C R+$ EX lost similar amounts of body weight $(-10 \pm 1 \%)$, fat mass $(-24 \pm 3 \%)$, visceral fat $(-27 \pm 3 \%)$, and had increased insulin sensitivity (CR: $40 \pm 20 \%, C R+$ EX: $66 \pm 22 \%$ ). Leptin was significantly decreased from baseline $(p<0.001)$ in both groups however TNF- $\alpha$ and IL-6 were not changed. hsCRP was decreased in CR + EX. There was no change in the expression of genes involved in macrophage infiltration (CD68, MIF, MCP-1, PAI-1) or inflammation (IL-6, TNF- $\alpha$, adiponectin) in either CR or CR + EX. Conclusion: A 10\% weight loss with a $25 \%$ CR diet alone or with exercise did not impact markers of systemic inflammation or the expression of inflammation-related adipose genes in overweight individuals.

Keywords: caloric restriction, inflammation, subcutaneous fat, exercise, aging, immune function

\section{INTRODUCTION}

Chronic low-grade systemic inflammation is a hallmark of obesity (Gregor and Hotamisligil, 2011). As adipose tissue expands, it is characterized by enlarged adipocytes and macrophage accumulation, resulting in increased circulating leptin, proinflammatory cytokines [interleukin-6 (IL-6), tumor necrosis factor-alpha (TNF- $\alpha)$ ] and chemokines [monocyte chemoattractant protein-1 (MCP-1)], and lower adiponectin levels (Rudman etal., 1990). These factors, indicative of chronic systemic low-grade inflammation, are believed to be involved in the pathogenesis of cardiovascular disease (Pai et al., 2004), insulin resistance and type 2 diabetes (Festa et al., 2000). Potential mechanisms linking obesity-associated low-grade inflammation and metabolic dysfunction include activation of cytokine or toll-like receptor signaling pathways which can access cellular targets directly or via chaperoning molecules. Consequently, three prominent kinases, JNK, IKK, and PKR, downstream of these signaling pathways have important roles in relaying stress signals throughout the cell (Gregor and Hotamisligil, 2011).

Interventions which reduce adipose tissue mass such as lowcalorie diet (LCD; Esposito etal., 2003; Clement et al., 2004) or bariatric surgery (Cancello et al., 2005) generally result in decreased systemic and local adipose tissue inflammation. However, the majority of these investigations have been performed in obese individuals (Esposito et al., 2003; Clement et al., 2004; Cancello et al., 2005; Dahlman et al., 2005; Viguerie et al., 2005; Franck et al., 2011). Given that overweight subjects have a strong tendency to transition to obesity, identifying whether inflammation perturbations occur during the overweight period may be clinically relevant and is currently not known (Singh et al., 2008; Herman et al., 2009). In addition, calorie restriction (CR), a dietary intervention that delivers reduced calories while maintaining proper nutrition has potent anti-inflammatory effects in primates (Kim etal., 1997) and in humans self-prescribing CR diets (Fontana et al., 2004). The anti-inflammatory effects of CR 
could be mediated by one or more of the following CR-induced changes; reduced adiposity and secretion of pro-inflammatory mediators, reduced oxidative stress, and increased insulin sensitivity.

The Pennington CALERIE study was a 24 -week study in young, overweight adults testing the hypothesis that CR improves biomarkers of longevity (Heilbronn et al., 2006). We have previously found that fasting insulin and core body temperature were reduced with $\mathrm{CR}$ while dehydroepiandrosterone sulfate (DHEA-S) was unchanged (Heilbronn et al., 2006). An exploratory endpoint of the study was to test the hypothesis that 24 weeks of moderate CR (25\%) would reduce markers of systemic inflammation and attenuate expression of pro-inflammatory genes in subcutaneous adipose tissue. We hypothesized that overweight individuals would have increased systemic and adipose tissue inflammation gene expression, which would be reduced by a $25 \%$ energy deficit by diet and/or aerobic exercise.

\section{MATERIALS AND METHODS ETHICS STATEMENT}

This study was conducted according to the principles expressed in the declaration of Helsinki. The study was approved by the Pennington Biomedical Research Center IRB and the Data Safety Monitoring Board of CALERIE. All participants provided written informed consent for the collection of samples and subsequent analysis.

\section{PARTICIPANTS}

Of the 599 individuals screened for the study, 551 were excluded (460 were ineligible; 91 withdrew during screening; Figure 1). Thirty-five overweight [ $25 \leq$ body mass index $(\mathrm{BMI})<30$ ] but otherwise healthy men ( 25 to $<50$ years) and pre-menopausal women ( 25 to $<45$ years) from the Pennington CALERIE study are included in this analysis (Heilbronn et al., 2006). Subject eligibility was assessed in three screening visits and with comprehensive testing. Participants were excluded if they smoked, exercised

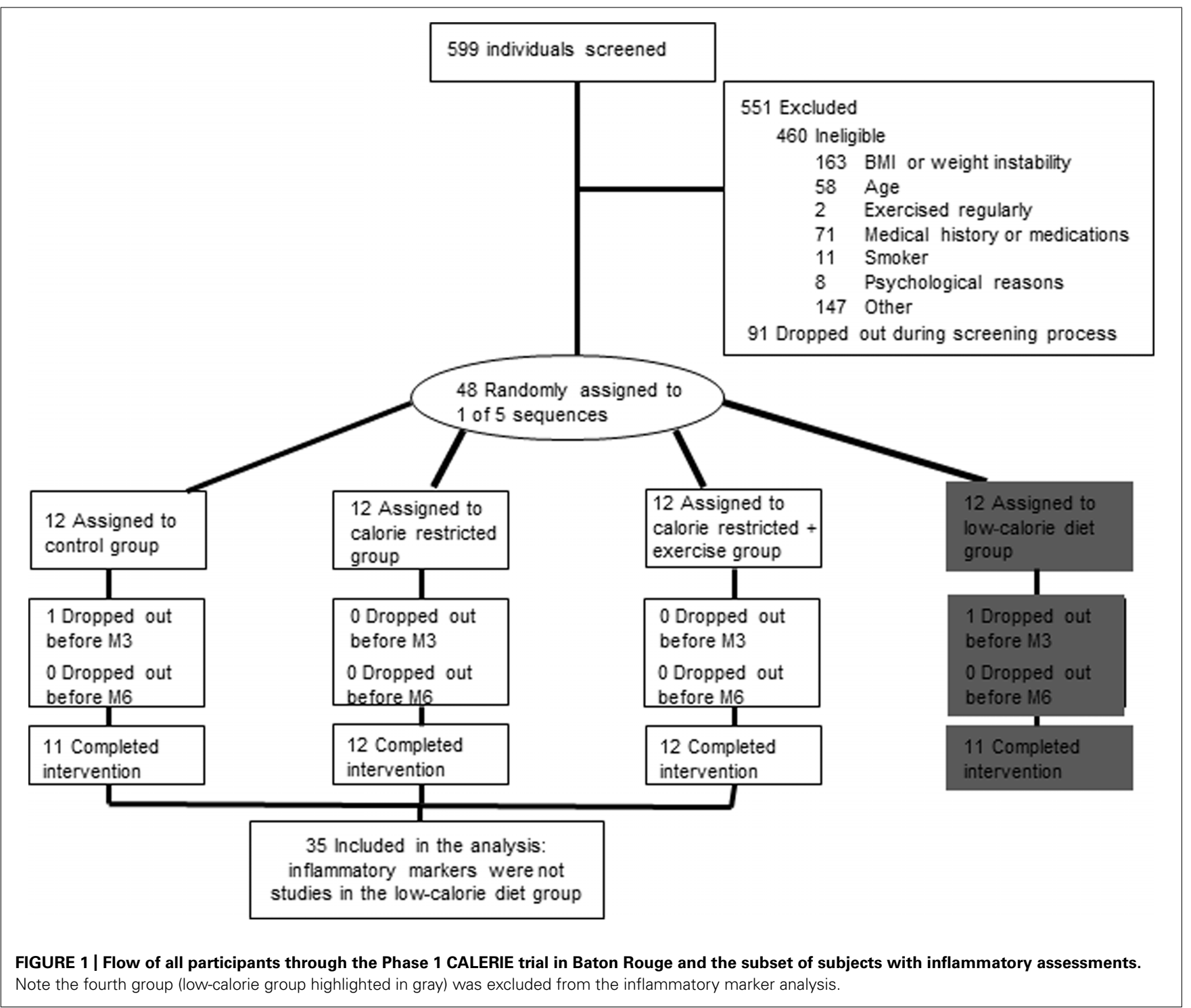


more than twice per week, were pregnant, lactating or postmenopausal, had a personal history of obesity (BMI never greater than $32 \mathrm{~kg} / \mathrm{m}^{2}$ ), cardiovascular disease, diabetes, or regularly used medications (except birth control). Details of the screening process and study population have been extensively described (Heilbronn et al., 2006). A copy of the full study protocol can be obtained at www.clinicaltrials.gov

\section{STUDY DESIGN}

Following a 5-week baseline period, subjects were randomized into one of four groups for 24 weeks: Control = healthy weight-maintenance diet based on the American Heart Association (AHA) Step 1 guidelines. (5M/6F), CR $=25 \% \mathrm{CR}$ from baseline energy requirements $(6 \mathrm{M} / 6 \mathrm{~F})$, caloric restriction + exercise $(\mathrm{CR}+\mathrm{EX})=12.5 \% \mathrm{CR}$ and $12.5 \%$ increase in exercise energy expenditure $(5 \mathrm{M} / 7 \mathrm{~F})$. The study also included a fourth group (LCD) however since the goal of this treatment group was to achieve a specific weight loss followed by weight maintenance (and not to sustain a defined level of CR), this group was excluded from the inflammation analyses.

\section{INTERVENTIONS}

Individualized energy intakes were prescribed from two consecutive measures of energy expenditure by doubly labeled water at baseline (Larson-Meyer et al., 2010). During 3 weeks at baseline and weeks 1-12 and 22-24 of the intervention, participants consumed a diet based on the AHA guidelines, 30\% calories from fat, $15 \%$ from protein, and 55\% from carbohydrate. The diets were prepared by the Metabolic Kitchen at the Pennington Biomedical Research Center. For weeks 13-22 participants followed their assigned dietary prescription by self-selection. Dietary intake and body weight were monitored weekly to ensure compliance. CR and Control participants were required to continue their usual pattern of physical activity throughout the study while participants in $\mathrm{CR}+\mathrm{EX}$ increased their energy expenditure by $12.5 \%$ above baseline through structured supervised aerobic exercise sessions, 5 days/week according to an individualized exercise prescription (Larson-Meyer et al., 2010).

\section{CLINICAL ASSESSMENTS}

Body composition by dual x-ray absorptiometry (Hologics QDR 4500A, Bedford, MA, USA), abdominal fat distribution by multislice computed tomography (GE Light Speed, General Electric, Milwaukee, WI, USA) and fasting blood and adipose tissue biopsies were collected during a 5-day inpatient stay at baseline and 24 weeks after the intervention (Larson-Meyer et al., 2010). Insulin sensitivity $(\mathrm{Si})$ and acute insulin response to glucose (AIRg) were determined by the modified frequently sampled intravenous glucose tolerance test (Heilbronn et al., 2006) at baseline and 24 weeks after the intervention. All clinical investigators conducting clinical assessments with the exception of the study physician were blinded to the treatment assignment.

\section{BIOCHEMICAL ASSAYS}

Highly sensitive C-reactive protein (hsCRP) was determined by chemiluminescent immunoassay (Immulite $2000^{\mathrm{TM}}$, Siemens Healthcare Diagnostics, Deerfield, IL, USA); TNF- $\alpha$ and IL-6 by immunoassay (Luminex $100^{\mathrm{TM}}$, Luminex Corp., Austin, TX, USA); and leptin and adiponectin concentrations by radioimmunoassay (Linco Research Inc., St Charles, MO, USA).

\section{Tissue collection and gene expression analysis}

Approximately, $350 \mathrm{mg}$ of subcutaneous adipose tissue was collected from the abdomen ( $5 \mathrm{~cm}$ to left/right of the umbilicus) using a Bergstrom needle. Repeat biopsies were obtained no less than $1 \mathrm{~cm}$ from the previous biopsy incision site, in compliance with standard clinical practice at our Center. Fat cell size was determined by the Multisizer-3 counter (Beckman Coulter, Fullerton, CA, USA) as previously described (Heilbronn et al., 2004). RNA from $\sim 100 \mathrm{mg}$ of tissue was isolated by column purification (Qiagen, Valencia, CA, USA) and yield determined by spectrophotometry (NanoDrop Technologies, Wilmington, DE, USA). From each RNA sample, $200 \mathrm{ng}$ was reverse transcribed to cDNA using the High Capacity cDNA Reverse Transcription kit (Applied Biosystems, Foster City, CA, USA). Relative quantification of mRNA expression was analyzed using ABI PRISM 7900 (Applied Biosystems, Branchburg, NJ, USA) and custom Taqman gene expression micro fluidic cards for TNF- $\alpha$ (Hs00174128_m1), IL-6 (Hs00985639_m1), macrophage marker (CD68, Hs00154355_m1), macrophage migration inhibitory factor (MIF, Hs00236988_g1), MCP-1 (Hs00234140_m1), plasminogen activator inhibitor-1 (PAI-1, Hs01126603_m1), and adiponectin (Hs00605917_m1). Samples were run in triplicate and expression levels were normalized to cyclophilin B (Hs00168719_m1). Cyclophilin B was not changed by treatment in either group (CR: $p=0.35, \mathrm{CR}+\mathrm{EX}: p=0.62$, Control: $p=0.76$ ) and there was no treatment effect $(p=0.37)$.

\section{STATISTICAL ANALYSES}

Data are presented as means \pm SEM. SAS Version 9.12 (SAS Institute, Cary, NC, USA) was used for analysis. The change and percent change from baseline to month 6 was calculated for all variables, and between group differences $(\mathrm{CR}, \mathrm{CR}+\mathrm{EX}$, Control) were tested by analysis of covariance with baseline values included in the model as covariates. Statistical significance for all multiple comparisons was adjusted using Tukey-Kramer to avoid type I errors. Statistical significance was considered when $p<0.05$.

\section{RESULTS \\ SUBJECT CHARACTERISTICS}

At baseline the groups did not differ with respect to demographic data, body weight, adiposity, or insulin sensitivity (Table 1). There were no associations between body weight, percent body fat, abdominal visceral fat mass, subcutaneous fat cell size, or insulin sensitivity and inflammation gene expression.

\section{Effects of CR on body weight, body composition, insulin sensitivity}

As previously reported (Heilbronn et al., 2006), 25\% energy deficit by diet alone (CR) or diet plus exercise $(\mathrm{CR}+\mathrm{EX})$ resulted in similar and significant reductions in body weight, fat mass, and abdominal visceral fat (Table 1). There was an improvement in insulin sensitivity however it only reached significance in $\mathrm{CR}+\mathrm{EX}$. 
Table 1 | Effect of caloric restriction alone and with exercise on body composition, insulin sensitivity, and systemic markers of inflammation.

\begin{tabular}{|c|c|c|c|c|c|c|}
\hline & \multicolumn{2}{|c|}{ Control (5M/6F) } & \multicolumn{2}{|c|}{$\mathrm{CR}(6 \mathrm{M} / 6 \mathrm{~F})$} & \multicolumn{2}{|c|}{$C R+E X(5 M / 7 F)$} \\
\hline & BL & $\% \Delta$ & BL & $\% \Delta$ & BL & $\% \Delta$ \\
\hline Age (year) & $37.7 \pm 2.2$ & - & $38.4 \pm 1.6$ & - & $35.5 \pm 1.6$ & - \\
\hline $\mathrm{BMI}\left(\mathrm{kg} / \mathrm{m}^{2}\right)$ & $27.6 \pm 2.0$ & $-1 \pm 1$ & $27.8 \pm 1.4$ & $-10 \pm 1$ & $27.5 \pm 1.6$ & $-10 \pm 1$ \\
\hline Weight (kg) & $82.3 \pm 2.9$ & $-1 \pm 1$ & $81.2 \pm 3.3$ & $-10 \pm 1^{*}$ & $82.1 \pm 3.1$ & $-10 \pm 1^{*}$ \\
\hline $\mathrm{FM}(\mathrm{kg})$ & $25.5 \pm 1.2$ & $-2 \pm 3$ & $24.9 \pm 1.8$ & $-24 \pm 3^{*}$ & $26.4 \pm 1.7$ & $-25 \pm 3^{*}$ \\
\hline VAT (kg) & $2.9 \pm 0.4$ & $-2 \pm 4$ & $3.2 \pm 0.5$ & $-28 \pm 4^{*}$ & $2.8 \pm 0.4$ & $-27 \pm 3^{*}$ \\
\hline Fat cell size $(\mu l)$ & $0.73 \pm 0.05$ & $4 \pm 7$ & $0.65 \pm 0.05$ & $-20 \pm 5^{*}$ & $0.70 \pm 0.04$ & $-26 \pm 6^{*}$ \\
\hline Insulin sensitivity (Si) & $2.8 \pm 1.2$ & $1 \pm 11$ & $3.3 \pm 1.7$ & $40 \pm 20$ & $3.4 \pm 0.4$ & $66 \pm 22^{*}$ \\
\hline \multicolumn{7}{|c|}{ Serum inflammatory markers } \\
\hline Adiponectin (ng/ml) & $2997 \pm 297$ & $6 \pm 4$ & $3253 \pm 302$ & $14 \pm 3$ & $3440 \pm 270$ & $7 \pm 4$ \\
\hline TNF- $\alpha(p g / m l)$ & $8.0 \pm 1.4$ & $44 \pm 11$ & $8.5 \pm 2.0$ & $64 \pm 31$ & $7.2 \pm 1.7$ & $79 \pm 43$ \\
\hline IL-6 (pg/ml) & $145.9 \pm 59.5$ & $9 \pm 14$ & $66.5 \pm 20.2$ & $44 \pm 21$ & $131.5 \pm 42.4$ & $5 \pm 8$ \\
\hline Leptin (ng/ml) & $19.3 \pm 3.8$ & $-2 \pm 8$ & $14.3 \pm 3.1$ & $-39 \pm 10^{*}$ & $18.3 \pm 3.7$ & $-52 \pm 8^{*}$ \\
\hline $\mathrm{CRP}(\mathrm{mg} / \mathrm{l})$ & $0.30 \pm 0.08$ & $-27 \pm 8$ & $0.25 \pm 0.07$ & $29 \pm 53$ & $0.15 \pm 0.03$ & $-27 \pm 8^{*}$ \\
\hline \multicolumn{7}{|c|}{ Gene expression (mRNA; AU) } \\
\hline Adiponectin & $0.84 \pm 0.06$ & $-6 \pm 6$ & $0.71 \pm 0.04$ & $11 \pm 11$ & $0.94 \pm 0.09$ & $36 \pm 47$ \\
\hline IL-6 & $4.00 \pm 0.53$ & $19 \pm 25$ & $3.87 \pm 0.74$ & $91 \pm 31$ & $12.30 \pm 5.98$ & $358 \pm 349$ \\
\hline
\end{tabular}

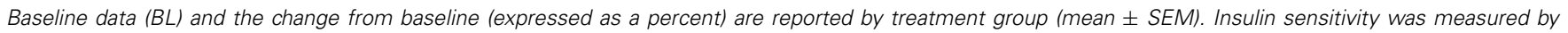

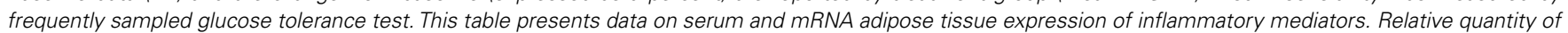

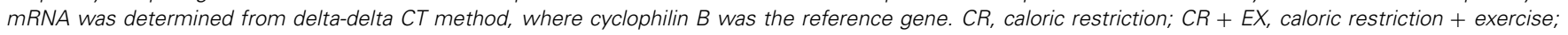

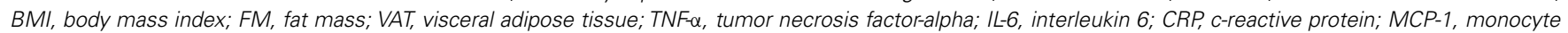
chemoattractant protein-1; MIF, macrophage migration inhibitory factor; PAl-1, plasminogen activator inhibitor-1.

${ }^{*}$ Denotes change is significantly different from baseline, $p<0.05$.

\section{Effects of CR on markers of systemic inflammation and expression of inflammation-related genes in subcutaneous adipose tissue}

Consistent with the loss of fat mass, there was a significant decrease in serum leptin concentrations in CR and CR + EX (Table 1). We also observed a significant increase in IL- 6 with CR, however, this effect was driven by one subject who had a $477 \%$ increase in IL-6 concentrations. When this subject was omitted from the analysis, the effect was no longer significant. Serum levels of hsCRP and TNF- $\alpha$ did not change from baseline in CR however hsCRP was significantly reduced in CR + EX (Table 1).

There was no change in the relative mRNA level for any of the genes measured: IL- 6 , TNF- $\alpha$, CD68, MIF, MCP-1, adiponectin, PAI-1 with the 24-week intervention (Figure 2). The percent change in weight, fat mass, visceral fat mass, abdominal adipocyte size, or insulin sensitivity was not related to the percent change mRNA expression of any inflammatory genes.

Given the lack of difference between CR and CR + EX, we pooled the two groups and tested the hypothesis that CR/CR + EX would decrease inflammation versus controls. We did not detect any differences between CR/CR + EX and controls in either serum markers or gene expression (data not shown).

\section{DISCUSSION}

In this study, overweight subjects completed a 24-week intervention producing a $25 \%$ energy deficit by diet alone (CR) or diet in conjunction with structured supervised exercise $(\mathrm{CR}+\mathrm{EX})$. The two intervention groups had similar reductions in body weight, total fat mass, and visceral fat and a wide range of circulating and gene expression inflammation markers were measured pre- and 


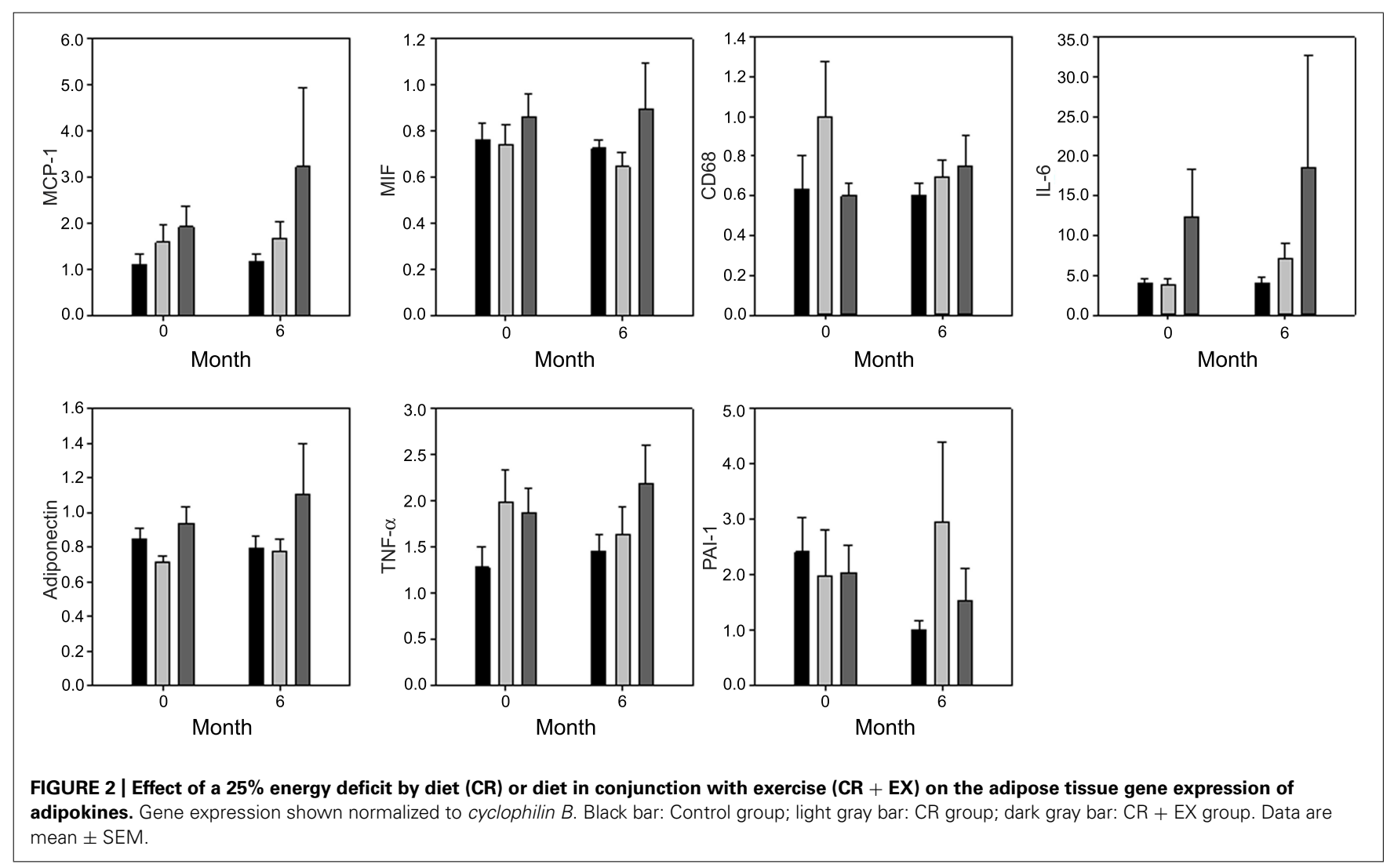

post-intervention. Contrary to our hypothesis, CR did not reduce circulating inflammatory markers or inflammation gene expression in subcutaneous adipose tissue. Furthermore CR + EX did not promote an anti-inflammatory response aside from a small, albeit significant lowering of hsCRP.

Several randomized controlled trials have been conducted to test the impact of weight loss by diet and/ or exercise on low-grade inflammation in obesity (Esposito et al., 2003; Clement et al., 2004; Christiansen etal., 2005, 2010; Bruun et al., 2006; Klimcakova et al., 2006; Polak et al., 2006; Capel et al., 2009). The consensus from these studies is that a threshold for weight loss (i.e., $10 \%)$ may be necessary to elicit an improvement in the inflammatory state (Forsythe et al., 2008). For example, a 12-week study found that serum markers (MIP-1 $\alpha$, IL-15) were reduced in obese subjects if weight loss exceeded $14.5 \%$ regardless of the type of intervention (diet or diet with exercise; Christiansen et al., 2010). However, mRNA expression of pro-inflammatory cytokines (IL-6 and TNF $\alpha$ ) and macrophage markers (CD68 and MCP-1) were not altered. In studies with little or no effect of weight loss on inflammatory outcomes (Klimcakova et al., 2006; Polak et al., 2007), it may be that the initial level of obesity was not sufficient for inducing systemic and/or local inflammation in subcutaneous adipose tissue. Certainly, in subjects with obesity and morbid obesity, weight loss by diet (Esposito et al., 2003; Clement et al., 2004; Christiansen et al., 2005) and/or exercise (Bruun et al., 2006; Christiansen et al., 2010) and bariatric surgery (Cancello et al., 2005) drastically reduces pro-inflammatory cytokines in serum and mRNA expression of adipokines in subcutaneous adipose tissue. We speculate that the healthy overweight subjects in our cohort who never had a BMI greater than $32 \mathrm{~kg} / \mathrm{m}^{2}$ did not have obesity-induced low-grade inflammation from the outset, thereby leading to a negative finding for diet and exercise mediated improvements in inflammation. It has been hypothesized that fasting/feeding cycles induce low-level inflammatory responses in metabolic cells from lean animals, and it is only when chronic nutrient excess occurs that the inflammatory response reaches a certain threshold and a more harmful inflammatory response is activated (Gregor and Hotamisligil, 2011). Indeed, even 8 weeks of overfeeding (3200-5800 kJ/day) in lean to overweight individuals resulting in $3-4 \%$ weight gain is not sufficient to alter circulating and local inflammation markers (Tam et al., 2010; Alligier et al., 2011). Furthermore, the baseline CRP levels in this study were considerably lower than CRP levels described in morbidly obese subjects (2-6 mg/l; Holdstock et al., 2005; Hofso et al., 2009). Coupled with the findings in the current study, it may be that a threshold of weight gain/loss is required for inflammation to be induced, or reversed.

Obesity-induced inflammation is especially present when adiposity is in the visceral depot (Alvehus et al., 2010) since several inflammatory markers such as PAI-1, MIF, CCL2 are preferentially expressed in visceral fat (Forsythe et al., 2008). Given that the inflammatory state in obesity is not improved by removal of subcutaneous fat with liposuction (Klein et al., 2004), a reduction of visceral fat in diet and exercise studies is probably most important (Chaston and Dixon, 2008). Therefore, measuring the expression of genes in the visceral fat, albeit impossible in most 
clinical studies, may provide further insights into the effects of diet and/or exercise on low-grade inflammation in overweight individuals. A limitation of our study is the relatively low sample size as our analysis was an exploratory end point of the parent study. Nevertheless, the sample size of this study was similar to previously published studies looking at the effects of diet and/or exercise interventions on inflammation (Forsythe et al., 2008).

In summary, our data indicates that even with a $10 \%$ weight loss and $30 \%$ reduction in visceral fat, there was no marked improvement in systemic or markers of inflammation in subcutaneous adipose tissue probably due to the general good health of our overweight and not obese participants.

\section{REFERENCES}

Alligier, M., Meugnier, E., Debard, C., Lambert-Porcheron, S., Chanseaume, E., Sothier, M., Loizon, E., Ait, H. A., Brozek, J., Scoazec, J. Y., Morio, B., Vidal, H., and Laville, M. (2011). Subcutaneous adipose tissue remodeling during the initial phase of weight gain induced by overfeeding in humans. J. Clin. Endocrinol. Metab. 97, E183-E192.

Alvehus, M., Buren, J., Sjostrom, M., Goedecke, J., and Olsson, T. (2010). The human visceral fat depot has a unique inflammatory profile. Obesity (Silver Spring) 18, 879-883.

Bruun, J. M., Helge, J. W., Richelsen, B., and Stallknecht, B. (2006). Diet and exercise reduce low-grade inflammation and macrophage infiltration in adipose tissue but not in skeletal muscle in severely obese subjects. Am. J. Physiol. Endocrinol. Metab. 290, E961-E967.

Cancello, R., Henegar, C., Viguerie, N., Taleb, S., Poitou, C., Rouault, C., Coupaye, M., Pelloux, V., Hugol, D., Bouillot, J. L., Bouloumie, A., Barbatelli, G., Cinti, S., Svensson, P. A., Barsh, G. S., Zucker, J. D., Basdevant, A., Langin, D., and Clement, K. (2005). Reduction of macrophage infiltration and chemoattractant gene expression changes in white adipose tissue of morbidly obese subjects after surgery-induced weight loss. Diabetes 54, 2277-2286.

Capel, F., Klimcakova, E., Viguerie, N., Roussel, B., Vitkova, M., Kovacikova, M., Polak, J., Kovacova, Z., Galitzky, J., Maoret, J. J., Hanacek, J., Pers, T. H., Bouloumie, A., Stich, V., and Langin, D. (2009). Macrophages and adipocytes in human obesity: adipose tissue gene expression and insulin sensitivity during calorie restriction and weight stabilization. Diabetes 58 , 1558-1567.

Chaston, T. B., and Dixon, J. B. (2008). Factors associated with percent change in visceral versus subcutaneous abdominal fat during weight loss: findings from a systematic review. Int. J. Obes. (Lond.) 32, 619-628.

Christiansen, T., Paulsen, S. K., Bruun, J. M., Pedersen, S. B., and Richelsen, B. (2010). Exercise training versus dietinduced weight-loss on metabolic risk factors and inflammatory markers in obese subjects: a 12-week randomized intervention study. Am. J. Physiol. Endocrinol. Metab. 298, E824-E831.

Christiansen, T., Richelsen, B., and Bruun, J. M. (2005). Monocyte chemoattractant protein-1 is produced in isolated adipocytes, associated with adiposity and reduced after weight loss in morbid obese subjects. Int. J. Obes. (Lond.) 29, 146-150.

Clement, K., Viguerie, N., Poitou, C., Carette, C., Pelloux, V., Curat, C. A., Sicard, A., Rome, S., Benis, A., Zucker, J. D., Vidal, H., Laville, M., Barsh, G. S., Basdevant, A., Stich, V., Cancello, R., and Langin, D. (2004). Weight loss regulates inflammation-related genes in white adipose tissue of obese subjects. FASEB J. 18, 1657-1669.

Dahlman, I., Linder, K., Arvidsson, N. E., Andersson, I., Liden, J., Verdich, C., Sorensen, T. I., and Arner, P. (2005). Changes in adipose tissue gene expression with energyrestricted diets in obese women. Am. J. Clin. Nutr. 81, 1275-1285.

Esposito, K., Pontillo, A., Di, P. C., Giugliano, G., Masella, M., Marfella, R., and Giugliano, D. (2003). Effect of weight loss and lifestyle changes on vascular inflammatory markers in obese women: a randomized trial. JAMA 289, 1799-1804.

Festa, A., D’Agostino, R. Jr., Howard, G., Mykkanen, L., Tracy, R. P., and Haffner, S. M. (2000). Chronic subclinical inflammation as part of the insulin resistance syndrome: the Insulin Resistance Atherosclerosis Study (IRAS). Circulation 102, 42-47.

Fontana, L., Meyer, T. E., Klein, S., and Holloszy, J. O. (2004). Long-term calorie restriction is highly effective in reducing the risk for atherosclerosis

\section{ACKNOWLEDGMENTS}

The authors would like to extend thanks to the remaining members of the Pennington CALERIE Research Team, staffs of the Inpatient Clinic and Metabolic Kitchen, Stacy Carling for laboratory assistance, and Xiaobing Fang for statistical support. We are profoundly grateful to all the volunteers for their generosity and time in completing this very rigorous study. This work was funded by the National Institutes of Health U01-AG20478 (Eric Ravussin), a NORC Center Grant 1P30 DK072476 and Dr. Leanne M. Redman is supported by K99HD060762. The funders had no role in study design, data collection and analysis, decision to publish, or preparation of the manuscript.

in humans. Proc. Natl. Acad. Sci. U.S.A. 101, 6659-6663.

Forsythe, L. K., Wallace, J. M., and Livingstone, M. B. (2008). Obesity and inflammation: the effects of weight loss. Nutr. Res. Rev. 21, 117-133.

Franck, N., Gummesson, A., Jernas, M., Glad, C., Svensson, P. A., Guillot, G., Rudemo, M., Nystrom, F. H., Carlsson, L. M., and Olsson, B. (2011). Identification of adipocyte genes regulated by caloric intake. J. Clin. Endocrinol. Metab. 96, E413-E418.

Gregor, M. F., and Hotamisligil, G. S. (2011). Inflammatory mechanisms in obesity. Annu. Rev. Immunol. 29, 415-445.

Heilbronn, L. K., de Jonge, L., Frisard, M. I., DeLany, J. P., LarsonMeyer, D. E., Rood, J., Nguyen, T., Martin, C. K., Volaufova, J., Most, M. M., Greenway, F. L., Smith, S. R., Deutsch, W. A., Williamson, D. A., and Ravussin, E. (2006). Effect of 6-month calorie restriction on biomarkers of longevity, metabolic adaptation, and oxidative stress in overweight individuals: a randomized controlled trial. JAMA 295, 1539-1548.

Heilbronn, L. K., Rood, J., Janderova, L., Albu, J. B., Kelley, D. E., Ravussin, E., and Smith, S. R. (2004). Relationship between serum resistin concentrations and insulin resistance in nonobese, obese, and obese diabetic subjects. J. Clin. Endocrinol. Metab. 89, 1844-1848.

Herman, K. M., Craig, C. L., Gauvin, L., and Katzmarzyk, P. T. (2009). Tracking of obesity and physical activity from childhood to adulthood: the Physical Activity Longitudinal Study. Int. J. Pediatr. Obes. 4, 281-288.

Hofso, D., Ueland, T., Hager, H., Jenssen, T., Bollerslev, J., Godang, K., Aukrust, P., Roislien, J., and Hjelmesaeth, J. (2009). Inflammatory mediators in morbidly obese subjects: associations with glucose abnormalities and changes after oral glucose. Eur. J. Endocrinol. 161, 451-458.

Holdstock, C., Lind, L., Engstrom, B. E., Ohrvall, M., Sundbom, M., Larsson, A., and Karlsson, F. A. (2005). CRP reduction following gastric bypass surgery is most pronounced in insulin-sensitive subjects. Int. J. Obes. (Lond.) 29, 1275-1280.

Kim, M. J., Aiken, J. M., Havighurst, T., Hollander, J., Ripple, M. O., and Weindruch, R. (1997). Adult-onset energy restriction of rhesus monkeys attenuates oxidative stress-induced cytokine expression by peripheral blood mononuclear cells. J. Nutr. 127, 2293-2301.

Klein, S., Fontana, L., Young, V. L., Coggan, A. R., Kilo, C., Patterson, B. W., and Mohammed, B. S. (2004). Absence of an effect of liposuction on insulin action and risk factors for coronary heart disease. N. Engl. J. Med. 350, 2549-2557.

Klimcakova, E., Polak, J., Moro, C. Hejnova, J., Majercik, M., Viguerie, N., Berlan, M., Langin, D., and Stich, V. (2006). Dynamic strength training improves insulin sensitivity without altering plasma levels and gene expression of adipokines in subcutaneous adipose tissue in obese men. J. Clin. Endocrinol. Metab. 91, 5107-5112.

Larson-Meyer, D. E., Redman, L., Heilbronn, L. K., Martin, C. K., and Ravussin, E. (2010). Caloric restriction with or without exercise: the fitness versus fatness debate. Med. Sci. Sports Exerc. 42, 152-159.

Pai, J. K., Pischon, T., Ma, J., Manson, J. E., Hankinson, S. E., Joshipura, K., Curhan, G. C., Rifai, N., Cannuscio, C. C., Stampfer, M. J., and Rimm, E. B. (2004). Inflammatory markers and the risk of coronary heart disease in men and women. N. Engl. J. Med. 351, 2599-2610.

Polak, J., Klimcakova, E., Moro, C. Viguerie, N., Berlan, M., Hejnova, J. Richterova, B., Kraus, I., Langin, D., and Stich, V. (2006). Effect of aerobic 
training on plasma levels and subcutaneous abdominal adipose tissue gene expression of adiponectin, leptin, interleukin 6 , and tumor necrosis factor alpha in obese women. Metabolism 55, 1375-1381.

Polak, J., Kovacova, Z., Jacek, M., Klimcakova, E., Kovacikova, M., Vitkova, M., Kuda, O., Sebela, M., Samcova, E., and Stich, V. (2007). An increase in plasma adiponectin multimeric complexes follows hypocaloric diet-induced weight loss in obese and overweight pre-menopausal women. Clin. Sci. (Lond.) 112, 557-565.

Rudman, D., Feller, A. G., Nagraj, H. S., Gergans, G. A., Lalitha, P. Y., Goldberg, A. F., Schlenker, R. A., Cohn, L., Rudman, I. W., and Mattson, D.
E. (1990). Effects of human growth hormone in men over 60 years old. N. Engl. J. Med. 323, 1-6.

Singh, A. S., Mulder, C., Twisk, J. W., van Mechelen, W., and Chinapaw, M. J. (2008). Tracking of childhood overweight into adulthood: a systematic review of the literature. Obes. Rev. 9, 474-488.

Tam, C. S., Viardot, A., Clement, K., Tordjman, J., Tonks, K., Greenfield, J. R., Campbell, L. V., Samocha-Bonet, D., and Heilbronn, L. K. (2010). Short-term overfeeding may induce peripheral insulin resistance without altering subcutaneous adipose tissue macrophages in humans. Diabetes 59, 2164-2170.

Viguerie, N., Vidal, H., Arner, P., Holst, C., Verdich, C., Avizou, S., Astrup,
A., Saris, W. H., Macdonald, I. A., Klimcakova, E., Clement, K., Martinez, A., Hoffstedt, J., Sorensen, T. I., and Langin, D. (2005). Adipose tissue gene expression in obese subjects during low-fat and high-fat hypocaloric diets. Diabetologia 48, 123-131.

Conflict of Interest Statement: The authors declare that the research was conducted in the absence of any commercial or financial relationships that could be construed as a potential conflict of interest.

Received: 06 February 2012; paper pending published: 20 February 2012; accepted: 29 March 2012; published online: 19 April 2012.
Citation: Tam CS, Covington JD, Ravussin E and Redman LM for the Pennington CALERIE Team (2012) Little evidence of systemic and adipose tissue inflammation in overweight individuals. Front. Gene. 3:58. doi: 10.3389/fgene. 2012.00058

This article was submitted to Frontiers in Genetics of Aging, a specialty of Frontiers in Genetics.

Copyright (c) 2012 Tam, Covington, Ravussin and Redman for the Pennington CALERIE Team. This is an openaccess article distributed under the terms of the Creative Commons Attribution Non Commercial License, which permits non-commercial use, distribution, and reproduction in other forums, provided the original authors and source are credited. 